Карпикова Ирина Серафимовна

кандидат экономических наук, доцент, доцент кафедры социологии и психологии Байкальского государственного университета

Нефедьева Елена Ивановна

кандидат экономических наук, доцент кафедры социологии и психологии Байкальского государственного университета

\section{ФЕНОМЕН СОЦИАЛЬНОГО ИЖДИВЕНЧЕСТВА В ОЦЕНКАХ НАСЕЛЕНИЯ (НА ПРИМЕРЕ ИРКУТСКОЙ ОБЛАСТИ) [1]}

\section{Аннотация:}

Практики социального иждивенчества в условиях функционирования социальных государств приобрели маситабный характер. Для современной России проблема ограничения данных проявлений весьма актуальна, но ее решение в определенной степени сдерживается недостатком достоверных научно обоснованных сведений о степени укорененности и содержании практик социального иждивенчества и паразитизма. В работе изложены результаты опроса населения, выступающего частью маситабного эмпирического социологчческого исследования проблемы социального иждивенчества на региональном уровне. В ходе анкетирования изучено отношение жителей Иркутской области к рассматриваемому феномену, а также получена оценка распространенности практик социального иждивенчества и паразитизма. Выявлено преимущественно нейтральное и слабо негативное отношение граждан к подобным проявлениям. Обозначены категории населения, которые, по мнению опрошенных, в большей степени склонны к социальному иждивенчеству, - безработные, инвалиды и лица пожилого возраста. Представлены оценки респондентов, свидетельствующие о широком распространении в социуме практик социального иждивенчества и паразитизма. Установлено влияние гендерных и возрастных характеристик респондентов на их мнение относительно проявлений социального иждивенчества: мужчины и молодежь более лояльны в выводах, нежели женщины и пожилые люди. Сформулированы предложения в области реализации мер экономико-правового характера по ограничению практик социального иждивенчества.

Ключевые слова:

социальное иждивенчество, социальный паразитизм, иждивение, категории населения, общественное мнение, социологическое исследование, население региона, Иркутская область.
Karpikova Irina Serafimovna

PhD in Economics, Associate Professor, Sociology and Psychology Department, Baikal State University

Nefedyeva Elena Ivanovna

PhD in Economics, Associate Professor Sociology and Psychology Department, Baikal State University

\section{THE PHENOMENON OF SOCIAL DEPENDENCY IN POPULATION ASSESSMENTS (BY A CASE STUDY OF THE IRKUTSK REGION) [1]}

Summary

Social dependent practices in the social state functioning have become large-scale in nature. For modern Russia, it is relevant to restrict such practices. However, the solution to this problem is hampered by a lack of the reliable evidence-based data on the extent and content of social dependency and parasitism. The paper presents the findings of a survey of the population, which is a part of a large-scale empirical sociological study on social dependency at the regional level. Based on the questionnaire, the authors examine the attitude of the population of the Irkutsk region to the phenomenon under review and assess the prevalence of social dependency and parasitism. The research reveals a predominantly neutral and slightly negative attitude of the population towards such manifestations. The study notes the categories of the population that, according to respondents, are more prone to social dependency, including unemployed, disabled, and elderly people. The respondents believe that social dependency and parasitism are widespread practices in society. The research reveals the impact of gender and age characteristics of respondents on their opinion on social dependency: men and young people are more loyal rather than women and older people. The proposals are made to implement the economic and legal measures to reduce social dependency.

Keywords social dependency, social parasitism, dependency, categories of population, public opinion, sociological survey, population of the region, Irkutsk region.

Мировой опыт наглядно демонстрирует прямую взаимозависимость между развитием институтов социального государства и возрастанием проявлений социального иждивенчества и паразитизма. Повышение уровня жизни и увеличение объема социальных гарантий неизбежно порождают иждивенческие настроения среди определенной части населения, что характерно и для современной России. Данное обстоятельство свидетельствует о необходимости постоянного совершенствования государственных механизмов социальной поддержки граждан [2, с. 173-174] на основе изучения содержания и трансформации практик социального иждивенчества и паразитизма, масштабов их распространения. 
Исследования феномена социального иждивенчества за рубежом весьма многочисленны, многоаспектны и опираются на обширную эмпирическую базу [3]. В России, несмотря на актуальность данной тематики, количество работ невелико, большинство из них посвящено рассмотрению феномена социального иждивенчества с историко-философрских, исторических и социокультурных позиций [4]. Незначительная часть публикаций касается отдельных сторон проблемы социального иждивенчества относительно некоторых категорий населения [5]. В то же время для принятия управленческих решений в области социальной политики по сдерживанию распространения практик социального иждивенчества и паразитизма необходимы научные данные, основанные на эмпирических исследованиях, всесторонне характеризующих состояние проблемы.

По нашему мнению, подобные эмпирические исследования целесообразно проводить на уровне региона, поскольку в России комплекс социозащитных мероприятий, обеспечивающих питательную среду для социального иждивенчества и паразитизма, фрормируется главным образом на региональном уровне, а проблемы регионов при реализации социозащитных практик типичны.

В настоящее время нами в составе научного коллектива реализуется проект «Влияние идей патернализма на поведенческие стратегии: исследование практик социального иждивенчества и социального паразитизма отдельных категорий населения», центральной частью которого является масштабное эмпирическое исследование, осуществляемое в Иркутской области. Отличительной чертой выполняемой работы стало совместное использование качественных и количественных научных стратегий [6], что позволяет получить всестороннее представление о масштабах распространенности и укоренения, содержании и специфике практик социального иждивенчества и паразитизма в современном российском социуме. Экспертные оценки, данные руководителями и специалистами социозащитной сферы региона в ходе проведения качественного интервью и фокус-группы в сентябре - ноябре 2017 г., дополнены информацией, полученной от населения, выступающего субъектом реализации иждивенческих и паразитических социальных практик.

Количественное социологическое исследование в виде анкетного опроса граждан Иркутской области, посвященное разным аспектам проблемы социального иждивенчества, проведено в июле - сентябре 2018 г. Выборочная совокупность в 1200 чел. стратифицирована по критериям пола, возраста и места проживания. Структура респондентов по данным признакам в целом соответствует демографическим характеристикам населения региона. Среди опрошенных женщины составили 57,5 \%, мужчины - 42,5 \%. Распределение участников анкетирования по возрасту выглядит следующим образом, \%: до 30 лет - 21,6, от 30 до 50 - 38,6, старше 50 лет - 39,8. Доля респондентов, проживающих в городах, равна 78 \%, в сельской местности - 22 \%, при этом в выборочную совокупность вошли жители крупных, средних и малых городов.

Кроме соблюдения стратификационных признаков, для избранной исследовательской стратегии было важно обеспечить наличие в выборочной совокупности представителей тех категорий населения, которые являются получателями социальных благ и услуг от государства и гипотетически склонны в той или иной мере к проявлению социального иждивенчества. Поэтому в число объектов изучения вошли представители таких страт, как многодетные и неполные семьи, лица из числа детей-сирот, мигранты, инвалиды, пенсионеры и др.

Среди исследовательских задач опроса следует выделить выяснение отношения граждан к феномену социального иждивенчества, а также их оценку распространенности социального иждивенчества и паразитизма.

Необходимо остановиться на понимании респондентами содержания понятия «социальное иждивенчество». С данной целью был задан вопрос о сходстве либо различии категорий «иждивение» и «иждивенчество». В ходе опроса установлено, что большинство населения (68,4 \% опрошенных) считает эти термины синонимичными, выбирая вариант ответа «для меня это одно и то же». Еще 16,8 \% (среди которых больше женщин и лиц старших возрастных групп) полагают, что «у этих понятий есть разное и общее»; только 14,5 \% отмечают разницу между ними - «считаю их абсолютно разными понятиями».

Респонденты, указавшие различия между категориями «иждивение» и «иждивенчество», соотнесли их как «необходимость, попечение» и «паразитизм, злоупотребление», как «вынужденная мера» и «умышленное поведение» соответственно. Некоторые из ответивших, поясняя разницу понятий, высказывались достаточно подробно: «первое - это выплаты нетрудоспособным (детям, пенсионерам, тяжелобольным), второе - нежелание работать при том, что есть возможность»; «первое означает жизнь за счет государства, а второе - за счет общества»; «первое это люди, которые не могут себя содержать и находятся на попечении других, второе - люди, которые могут себя сами обеспечить, но не хотят»; «первое - человек находится на попечении кого-либо (инвалид, ребенок, пенсионер), а второе - осознанное тунеядство, есть возможность работать, нет желания, формируют потребительское отношение»; «первое - когда человек по объективным причинам не может сам себя обеспечить, а второе - когда человек без уважительной причины не хочет себя обеспечивать и пользуется ресурсами других». 
Социальное иждивенчество участники исследования определили как «потребительский, паразитарный образ жизни взрослого трудоспособного человека, способного, но не желающего себя обеспечить самостоятельно»; «приспособление человека к жизни за счет других»; «стремление жить, рассчитывая на чью-то помощь, не прилагая собственных усилий для улучшения материального положения»; «нежелание самому себя обеспечивать, постоянное стремление человека жить за счет других». Стоит отметить, что в ответах на открытые вопросы анкеты респонденты были достаточно активны, развернуто выражали свою точку зрения, что косвенно свидетельствует об интересе граждан к теме опроса.

К социальному иждивенчеству могут быть склонны представители разных категорий населения, по разным причинам и в разных масштабах использующие подобные практики. Важнейшей задачей опроса стало выявление таких страт. Отметим, что этот же вопрос задавался ранее в ходе экспертного интервью, поэтому особый интерес представляет сравнение мнений экспертов и населения (таблица 1).

Таблица 1 - Распределение ответов на вопрос: «Какие категории населения в большей степени склонны к социальному иждивенчеству?»

\begin{tabular}{|c|c|c|c|c|}
\hline \multirow{2}{*}{ Категория } & \multicolumn{2}{|c|}{$\begin{array}{c}\text { Оценка экспертов } \\
{[7, \text { с. 169] }}\end{array}$} & \multicolumn{2}{|c|}{ Оценка населения } \\
\hline & $\begin{array}{c}\text { Количество } \\
\text { ответивших, \% }\end{array}$ & $\begin{array}{c}\text { Ранг } \\
\text { ответа }\end{array}$ & $\begin{array}{c}\text { Количество } \\
\text { ответивших, \% }\end{array}$ & $\begin{array}{c}\text { Ранг } \\
\text { ответа }\end{array}$ \\
\hline Пожилые и престарелые люди & 13,9 & 4 & 14,6 & 3 \\
\hline Многодетные семьи & 5,7 & 6 & 9,6 & 5 \\
\hline Студенты & 3,3 & 7 & 9,4 & 6 \\
\hline Инвалиды & 22,1 & 2 & 15,3 & 2 \\
\hline Матери-одиночки (отцы-одиночки) & 0,8 & 8 & 3,1 & 8 \\
\hline Безработные & 15,6 & 3 & 20,6 & 1 \\
\hline Лица без определенного места жительства & 7,4 & 5 & 8,5 & 7 \\
\hline Дети, оставшиеся без попечения родителей (сироты) & 23,8 & 1 & 10,4 & 4 \\
\hline Мигранты, беженцы, вынужденные переселенцы & 7,4 & 5 & 8,5 & 7 \\
\hline
\end{tabular}

В ответах экспертов и респондентов из числа населения прослеживаются как сходства, так и различия. Оценки специалистов сконцентрированы на определенных категориях, тогда как рядовые опрошенные демонстрируют большее разнообразие при выборе вариантов ответов. Данное обстоятельство объясняется различиями в обыденном и профессиональном опыте, на котором основываются высказанные мнения.

В то же время ранжирование ответов, отражая различия в распределении мест между категориями (эксперты на первое место ставят детей-сирот, а обычные граждане - безработных), позволяет четко определить страты, которые являются лидерами в аспекте реализации иждивенческих практик, по мнению как специалистов, так и рядовых респондентов. К ним относятся инвалиды, безработные, дети-сироты, а также пожилые и престарелые люди. Показателен фракт, что на последнее место по склонности к проявлению иждивенчества обе группы поместили такую категорию, как матери-, отцы-одиночки.

Кроме перечисленных категорий населения, респонденты отнесли к числу социальных иждивенцев лиц, отбывающих наказание в местах лишения свободы, а также «тунеядцев», т. е. неработающих трудоспособных лиц в экономически активном возрасте.

В ответах на данный вопрос респондентов из числа населения выявлена некоторая зависимость оценок от возраста опрошенных. В значительной мере выбор члена определенной возрастной группы связан с той категорией лиц, склонных к социальному иждивенчеству, к которой он потенциально мог бы относиться по возрасту. Так, пожилых граждан в большей степени считают склонными к иждивенчеству участники исследования в возрасте от 50 лет; представителей многодетных семей - респонденты средней возрастной группы 30-39 лет; студентов и лиц из числа детей-сирот чаще всех относят к социальным иждивенцам опрошенные до 30 лет.

Считают ли сами себя социальными иждивенцами граждане, принявшие участие в опросе? На данный вопрос положительно ответили только 6,7 \% респондентов, объясняя свою позицию рядом обстоятельств. Во-первых, в их числе есть трудоспособные лица, которые не работают по разным причинам и проживают за счет помощи со стороны родственников («временно без работы, но ищу работу»; «часто помогают родственники»; «денег не хватает, живем на помощь родителей, на их пенсию»; «на содержании у детей»; «пока учусь и живу на средства родителей»; «никогда не работал и не ищу работу»; «удовлетворяю потребности за счет близких родственников»). Во-вторых, среди людей, признавших себя социальными иждивенцами, выявлены те, кто нетрудоспособен частично или полностью и находится на иждивении у государства, получая различные социальные выплаты и пользуясь льготами. Анализ данных показывает, что среди признавших себя социальными иждивенцами трудоспособных гораздо больше, чем нетрудоспособных. 
Отрицательный ответ на поставленный вопрос дали 58,1 \% респондентов. Участники исследования, не считающие себя социальными иждивенцами, поясняют это следующим образом: «стараюсь работать и покрывать свои расходы сам»; «работаю и подрабатываю»; «всегда ищу возможности для дополнительного заработка»; «всегда самостоятельно работал и ни от кого не зависел»; «государство мне не помогает»; «не на кого надеяться, все знакомые и близкие в такой же ситуации»; «живу на доходы от трудовой деятельности»; «зарабатываю сам и помогаю другим»; «занимаюсь предпринимательством, чтобы иметь достаточный доход»; «заработали пенсию и ведем свое хозяйство»; «сам обеспечиваю себя и своих детей, не рассчитывая на государство». Еще 35,2 \% опрошенных затруднились с ответом. Возможно, часть из них не желает признавать факт своего социального иждивенчества и уходит таким способом от ответа.

Помимо выражения самооценки респондентам было предложено ответить на вопрос, есть ли в их ближайшем окружении, среди родных, друзей и знакомых, лица, поведение которых можно отнести к социальному иждивенчеству и паразитизму. Как установлено в процессе исследования, мнения опрошенных по этому поводу разделились почти поровну. Утвердительных ответов о наличии у родных и друзей иждивенческого образа жизни оказалось 41,0 \%, отрицательных - об отсутствии среди ближайшего окружения практик социального иждивенчества - 41,4, при этом 17,6 \% затруднились с оценкой. Участники опроса, утвердительно ответившие на данный вопрос, указали на конкретные проявления социального иждивенчества среди родственников и знакомых (таблица 2).

Таблица 2 - Распределение ответов респондентов на вопрос: «В чем проявляются иждивенческие настроения и поведение среди вашего ближнего окружения?», \%

\begin{tabular}{|l|c|}
\hline \multicolumn{1}{|c|}{ Вариант ответа } & Количество ответивших \\
\hline Не работают, живут на материальную помощь родных & 25,9 \\
\hline Не работают, живут на социальную помощь государства & 20,0 \\
\hline Не работают, но ищут работу & 19,5 \\
\hline Живут на доход от случайных неофициальных заработков & 12,5 \\
\hline Работают неофициально, зарплату получают «в конверте», не платят налоги & 10,3 \\
\hline Работают, но живут не только на свой трудовой доход & 8,3 \\
\hline Другое & 3,5 \\
\hline
\end{tabular}

Среди опрошенных, выбравших вариант ответа «другое», наиболее часто встречались следующие высказывания по поводу проявления иждивенчества со стороны друзей и родных: «употребляют алкоголь»; «не работают и не хотят искать работу».

Почти половина респондентов (47,3 \%) определили личное отношение к людям, склонным к социальному иждивенчеству и паразитизму, как нейтральное и безразличное, 33,5 \% относятся к таким людям негативно. Крайние оценки присущи незначительному количеству опрошенных: агрессивное отношение выразили 2,3 \%, примерно столько же (2,9 \%) относятся к лицам, проявляющим иждивенческие настроение и поведение, положительно и даже с одобрением их жизненной позиции. Затруднились с ответом на данный вопрос 14,0 \% участников исследования. Среди людей с нейтральной оценкой превалируют мужчины и молодежь, а негативное отношение больше свойственно респондентам старших возрастных групп и женщинам.

В анкету был включен ряд вопросов, позволяющих уточнить ранее высказанные позиции участников опроса об их отношении к проявлениям социального иждивенчества в обществе. Например, на вопрос о возможности и необходимости введения в Административный кодекс РФ статьи «за тунеядство» были даны следующие ответы, \%: 40,6 поддерживают данную инициативу, несколько больше, 32,3, высказались за недопустимость ее введения, 27,1 затруднились с ответом. Распределение отвечавших по возрасту показало, что респонденты старших возрастов активно поддерживают предложенную идею, а опрошенные из числа молодежи, напротив, в меньшей степени согласны с перспективой введения санкций за тунеядство.

Полученные результаты позволяют сделать ряд выводов. Во-первых, в обыденном сознании отсутствует четкий водораздел между понятиями «иждивение» и «иждивенчество», что, однако, не мешает гражданам на интуитивном уровне определять свое отношение к практикам социального иждивенчества и лицам, склонным к их применению, которое преимущественно носит нейтральный либо слабо негативный характер.

Во-вторых, граждане признают широкое распространение в обществе практик, характеризующих иждивенческие позиции некоторых представителей социума, - более 40 \% опрошенных отметили, что в их ближайшем окружении присутствуют социальные иждивенцы, хотя по отношению к самим себе респонденты относятся менее критично. Среди категорий населения, в большей степени подверженных влиянию иждивенческих установок, были в первую очередь названы безработные, инвалиды и престарелые. 
Наконец, при проведении опроса были выявлены гендерные и возрастные различия в оценках участников. Общая тенденция выглядит следующим образом: мужчины и респонденты молодого возраста более терпимы к проявлениям социального иждивенчества, осуждают его в меньшей степени, чем женщины и пожилые люди, что объясняется различиями жизненного опыта и современными гендерными социальными ролями. В то же время лояльность молодежи к иждивенческим поведенческим установкам является для социума тревожным симптомом, поскольку в ближайшем будущем без должного внимания общества может обернуться расширением поведенческих деформаций и даже девиаций.

Данные населением и экспертами оценки ситуации с распространением феномена социального иждивенчества позволяют определить некоторые направления деятельности по его ограничению, находящиеся в экономико-правовом поле. В сфере труда и занятости необходима активизация усилий по выявлению и противодействию теневой (неформальной) занятости и, соответственно, сокрытию трудовых доходов, неуплате налогов. Также весьма актуально явление «скрытой» безработицы, состоящее в отсутствии стремления искать работу или неготовности к ней приступить, что требует формирования механизма установления и ограничения подобных практик в системе содействия занятости.

Значительные возможности по ограничению иждивенческих поведенческих стратегий содержатся в усовершенствовании нормативно-правовой базы. Прежде всего необходимо перевести из морально-этической плоскости в правовую понятие «иждивенчество» как основание при определении санкций и превентивных мер по отношению к лицам с иждивенческим и паразитическим образом жизни.

Требуется пересмотр нормативно-правовых основ для реализации некоторых социозащитных мер. Существующие на сегодняшний день противоречия и недоработки в законодательстве о социальных правах и гарантиях отдельных категорий граждан дают возможность фоормирования иждивенческих практик. Примером является реализация прав детей-сирот в области содействия их занятости и профессионального образования, а также их жилищных прав. Кроме того, в целях профилактики практик социального иждивенчества среди категорий населения, склонных к их проявлениям, необходима модификация условий предоставления и размеров получаемых ими региональных социальных выплат.

\section{Ссылки и примечания:}

1. Статья подготовлена при финансовой поддержке РФФИ, проект «Влияние идей патернализма на поведенческие стратегии: исследование практик социального иждивенчества и социального паразитизма отдельных категорий населения» № 17-03-00477-ОГН.

2. Седых О.Г. Социальное иждивенчество: причины возникновения и историческая ретроспектива // Историческая и социально-образовательная мысль. 2018. Т. 10, № 3-1. С. 172-178.

3. Bradshaw J., Mayhew E. Public Attitudes to Dependency and the Welfare State // International Journal of Market Research 2004. Vol. 46 (4). P. 49-64. https://doi.org/10.1177/147078530404600109; Kathy D. Breaking the Cycle: Welfare Dependency and Family Planning // Policy \& Practice of Public Human Services. 2002. Vol. 6, no. 4 ; Younes M. Three Welfare Recipients: the Journey from Dependency to Self-Sufficiency. Lincoln, 1996 ; Zinn D. Welfare Dependency as the Language of Social Control // Sage Sourcebooks for the Human Services Series. 1987. Vol. 4. P. 216-257.

4. Жмакина М.О. Социальное иждивенчество как результат политики социального государства в современном российском обществе // Социология в современном мире: наука, образование, творчество. 2014. № 6. С. 399-403 ; Мосейко В.В., Фролова Е.А. Социальное государство vs социальное иждивенчество // Вестник Томского государственного педагогического университета. 2014. № 8 (149). С. 102-107 ; Сидорина Т.Ю. Операция Welfare State: решило ли государство всеобщего благосостояния проблемы идеального государства? // Terra economicus. 2012. № 3. C. 8499 ; Шаровская А.В. Социальное иждивенчество как проявление проблемы самоактуализации личности общества потребления // Исторические, фрилософские, политические и юридические науки, культурология и искусствоведение. Вопросы теории и практики. 2012. № 10-1. С. 205-208.

5. Басин М.А., Хаидов С.К. Иждивенческая позиция личности маргинальной женщины, находящейся в трудной жизненной ситуации, как негативный фрактор социализации ребенка // Психическая депривация детей в трудной жизненной ситуации: образовательные технологии профилактики, реабилитации, сопровождения. М., 2013. С. 125-134 ; Седых О.Г. Взаимодействие власти и бизнеса в решении жилищных проблем детей-сирот как механизм контроля и сдерживания социального иждивенчества // Baikal Research Journal. 2018. Т. 9, № 2. C. 10. https://doi.org/10.17150/24116262.2018.9(2).10 ; Шевелева Н.П., Кузнецов И.С. Предпосылки формирования социального иждивенчества в среде российской молодежи // Теория и практика общественного развития. 2015. № 18. С. 21-23.

6. Бахматова Т.Г. Исследовательский потенциал количественного и качественного подходов в социальной работе // Известия Иркутской государственной экономической академии (Байкальский государственный университет экономики и права). 2010. № 5. С. 28-35.

7. Карпикова И.С., Нефедьева Е.И., Седых О.Г. Социальное иждивенчество и паразитизм в продуцировании противоправного поведения // Всероссийский криминологический журнал. 2018. Т. 12, № 2. С. 165-177. https://doi.org/10.17150/2500-4255.2018.12(2).165-177.

\section{References:}


Irkutskoy gosudarstvennoy ekonomicheskoy akademii (Baykal'skiy gosudarstvennyy universitet ekonomiki i prava), no. 5, pp. 2835, (in Russian).

Basin, MA \& Khaidov, SK 2013, 'The Dependency of the Personality of a Marginal Woman Facing Hardship as a Negative Factor in the Child's Socialization', Psikhicheskaya deprivatsiya detey v trudnoy zhiznennoy situatsii: obrazovatel'nyye tekhnologii profilaktiki, reabilitatsii, soprovozhdeniya, Moscow, pp. 125-134, (in Russian).

Bradshaw, J \& Mayhew, E 2004, 'Public Attitudes to Dependency and the Welfare State', International Journal of Market Research, vol. 46 (4), pp. 49-64. https://doi.org/10.1177/147078530404600109.

Karpikova, IS, Nefedyeva, El \& Sedykh, OG 2018, 'Social Dependence and Parasitism in Inducing Unlawful Behavior', Russian Journal of Criminology, vol. 12, no. 2, pp. 165-177. https://doi.org/10.17150/2500-4255.2018.12(2).165-177.

Kathy, D 2002, 'Breaking the Cycle: Welfare Dependency and Family Planning', Policy \& Practice of Public Human Services, vol. 6 , no. 4

Moseyko, VV \& Frolova, EA 2014, 'The Welfare State vs. Social Dependency', Vestnik Tomskogo gosudarstvennogo pedagogicheskogo universiteta, no. 8 (149), pp. 102-107, (in Russian).

Sedykh, OG 2018a, 'Interaction of Authorities and Business in Solving Housing Problems for Orphaned Children as a Mechanism of Control and Moderation of Social Dependency', Baikal Research Journal, vol. 9, no. 2, p. 10. https://doi.org/10.17150/2411-6262.2018.9(2).10.

Sedykh, OG 2018b, 'Social Dependency: Causes and Historical Retrospective', Istoricheskaya i sotsial'no-obrazovatel'naya mysl', vol. 10, no. 3-1, pp. 172-178, (in Russian).

Sharovskaya, AV 2012, 'Social Dependency as a Problem of Self-Actualization of the Personality in a Consumer Society', Istoricheskiye, filosofskiye, politicheskiye i yuridicheskiye nauki, kul'turologiya i iskusstvovedeniye. Voprosy teorii i praktiki, no. 101, pp. 205-208, (in Russian).

Sheveleva, NP \& Kuznetsov, IS 2015, 'Preconditions of Social Dependency of Russian Youth', Teoriya i praktika obshchestvennogo razvitiya, 2015. no. 18, pp. 21-23, (in Russian).

Sidorina, TYu 2012, 'Welfare State Procedure: Has the Welfare State Solved the Problems of an Ideal State?', Terra economicus, no. 3, pp. 84-99, (in Russian).

Younes, M 1996, Three Welfare Recipients: the Journey from Dependency to Self-Sufficiency, Lincoln.

Zhmakina, MO 2014, 'Social Dependency as a Result of the Welfare State Policy in Modern Russian Society', Sotsiologiya v sovremennom mire: nauka, obrazovaniye, tvorchestvo, no. 6, pp. 399-403, (in Russian).

Zinn, D 1987, 'Welfare Dependency as the Language of Social Control', Sage Sourcebooks for the Human Services Series, vol. 4 , pp. $216-257$. 